University of South Carolina

Scholar Commons

8-1983

\title{
Presidential Popularity and Macroeconomic Performance: Are Voters Really So Naive?
}

Henry W. Chappell Jr.

chappell@moore.sc.edu

Follow this and additional works at: https://scholarcommons.sc.edu/econ_facpub

Part of the Economics Commons

Publication Info

Review of Economics and Statistics, Volume 65, Issue 3, 1983, pages 385-392.

http://www.mitpressjournals.org/loi/rest

(C) 1983 by The MIT Press

This Article is brought to you by the Economics Department at Scholar Commons. It has been accepted for inclusion in Faculty Publications by an authorized administrator of Scholar Commons. For more information, please contact digres@mailbox.sc.edu. 


\title{
PRESIDENTIAL POPULARITY AND MACROECONOMIC PERFORMANCE: ARE VOTERS REALLY SO NAIVE?
}

\author{
Henry W. Chappell, Jr.*
}

$\mathrm{F}$ OLLOWING the pioneering work of Kramer (1971), numerous studies have analyzed the relationships between the macroeconomic performance of political administrations and their popularity or vote-getting ability. Kramer's work showed that the aggregate congressional vote for an incumbent party can be explained rather well by variables indicating recent economic performance. Subsequent works have extended Kramer's research by explaining presidential vote or Gallup Poll popularity data with similar models. ${ }^{1}$

On one point almost all of these studies agree: ${ }^{2}$ votes and popularity can be explained well by models which suppose that voters judge policymakers on the basis of retrospective evaluation of past macroeconomic outcomes. Most authors interpret their results as being supportive of the hypothesis of "rational" voters, since the evidence indicates that voting decisions are not based purely upon personalities, party affiliation, or chance. Kramer argued that if voters regard past macroeconomic performance of an administration to be indicative of future performance, then a concern with past performance indicates a concern for future performance. Voters who simply extrapolate from the past to predict the future are rather naive, however. A "sophisticated" voter, who has an understanding of the important intertemporal constraints embodied in the structure of the economy, would be able to forecast future consequences of current policy choices more accurately

Received for publication February 4, 1982. Revision accepted for publication July 30, 1982.

* University of South Carolina.

I am grateful for helpful comments provided by Ray Fair, Douglas Hibbs, William Keech, Daniel Richards, Abel L. Da Costa Fernandes, and an anonymous referee. I also wish to thank William Keech for providing me with the Gallup Poll data on presidential approval rates. Aurel Schubert provided excellent research assistance.

${ }^{1}$ Fair (1978a), Bloom and Price (1975), Arcelus and Meltzer (1975), and Pollard (1981 a, 1981b) have all estimated models to explain voting, while Frey and Schneider (1978) and Hibbs (1982a, 1982b) have developed models to explain presidential popularity.

${ }^{2}$ An exception is provided by Arcelus and Meltzer (1975). than one who simply extrapolates. If votes and popularity are simply functions of past outcomes, then voters must either be ignorant of the basic structure of the economy, or unconcerned with the future.

The supposition that voters are so naive might run counter to the intuition of most economists, who generally assume individual rationality as a central behavioral postulate. Nevertheless, the empirical results noted above have been accepted by many as evidence that voters do misperceive their own long-run interest. The implications of the naive voter hypothesis for macroeconomic policymaking are disturbing. Nordhaus (1975) has developed a model which shows that voter naiveté can encourage vote maximizing politicians to induce political business cycles and an inflationary bias. There is some, but not unanimous, empirical support for the existence of politically motivated business cycles, and casual empiricism also suggests that politicians themselves believe in the naive voter. ${ }^{3}$

While studies show that empirical evidence is consistent with the notion that voters are concerned with the recent past, the results do not reject a "sophisticated" voter hypothesis. None of the aforementioned studies has tested a model consistent with a sophisticated voter hypothesis, i.e., a model in which voters understand what outcomes are feasible in the long and short runs, and are concerned with future as well as current and past economic performance. In this paper we develop such a model and estimate it using Gallup Poll data on presidential popularity. Results of this model are compared to results from a "naive" voter model similar to those employed in previous research.

\footnotetext{
${ }^{3}$ Nordhaus (1975) and Tufte (1978) have provided evidence of political business cycles for a number of Western democracies, and Frey and Schneider (1978) and Maloney and Smirlock (1981) have estimated policy "reaction" functions suggesting that the timing of elections affects policymaking. See Tufte for a discussion of casual empirical evidence indicating that politicians believe that current economic conditions affect electoral outcomes.
} 
MacRae (1977, 1981) provides the only past research which has attempted to assess whether the electorate is best characterized as naive or sophisticated. His procedure provides only an indirect test, however. MacRae assumes that political administrations choose policies which maximize a vote function. He then determines whether actual policy choices more closely resemble the solution to a vote maximization problem in which voters are assumed to be naive or one in which they are assumed to be sophisticated. MacRae found that the sophisticated voter hypothesis performed as well or better than the naive voter hypothesis in a variety of time periods. If political administrations do not actually choose policies which maximize a vote function, then it is not clear what implications MacRae's results have regarding the question of voter sophistication. The fact that presidents fail to induce the political business cycles which would maximize votes under the naive voter hypothesis could mean that voters are not naive, or it could mean that the president does not implement those policies which would maximize votes. MacRae's results are important in that they show that political business cycles may be of limited consequence, but a direct test may shed more light on the question of whether voters are sophisticated or naive.

\section{Measuring Economic Performance}

Conventional popularity models have assumed that voters look at past inflation rates, unemployment rates, and perhaps growth of output in evaluating an administration's performance. Fair (1978b) has suggested that a more reasonable performance measure, one which would be embraced by sophisticated voters concerned with current and future welfare, would consider what combinations of unemployment and inflation were actually feasible in various periods, and would consider the likely future consequences of policies currently in effect. Fair noted that "optimal" policies could be found by solving a series of complex control problems. Given that "welfare" can be expressed as a specific function of current and future macroeconomic outcomes, and given a system of equations modelling the structure of the economy, one could determine welfare maximizing trajectories for policy instruments. Each quarter, with new information available, new optimal policy plans could be developed. Fair proposed a measure of economic performance for an administration based on the difference between the level of welfare which would result over an extended time period given the actual policy choices made by the administration, and the level which would have resulted if optimal policies had been chosen.

To test the sophisticated voter hypothesis we could compute a measure similar to that proposed by Fair and use it as an independent variable in an equation to explain presidential popularity. But doing so would require us to develop and estimate a macroeconometric model and to solve a large number of optimal control problems. Determining appropriate parameter values for the objective function characterizing preferences for output versus price stability would compound the computational task. Although such an undertaking might be feasible if the model of the economy were quite simple, we have chosen to employ a less cumbersome procedure in developing our popularity model. It is convenient to begin by discussing the model of the economy underlying our analysis.

We assume that the structure of the economy can be approximated by an accelerationist Phillips curve embodied in the following equations: ${ }^{4}$

$$
\begin{aligned}
& \dot{P}_{t}=\sum_{i=1}^{N} m_{i} \dot{P}_{t-i}+f\left(Z_{t}\right)+e_{t}, \quad f^{\prime}\left(Z_{t}\right)>0 \\
& \sum_{i=1}^{N} m_{i}=1
\end{aligned}
$$

where

$$
\begin{aligned}
Z_{t} & =Q_{t} / Q N_{t}-1 \\
Q_{t} & =\text { the actual rate of output in period } t \\
Q N_{t} & =\text { the "natural" rate of output in period } t \\
\dot{P}_{t} & =\text { inflation in period } t \\
e_{t} & =\text { a random error term. }
\end{aligned}
$$

This model implies that there exists a short-run tradeoff between the rate of inflation and output (hence unemployment), but no tradeoff in the long

\footnotetext{
${ }^{4}$ Although the model presented in equations (1) and (2) is usually derived under the assumption of "adaptive" inflationary expectations, it may also approximate an economy in which individuals have "rational" expectations, but one in which policy actions are not always fully anticipated or markets do not instantaneously adjust to equilibrium (see Fischer (1977)). We assume that policymakers can influence real economic variables, without ruling out the possibility of rational expectations.
} 
run. Essentially the equations assume that shortrun Phillips curves are negatively sloped, but that the long-run Phillips curve is vertical. ${ }^{5}$ If the incumbent administration adjusts monetary and fiscal policies so that actual output, $Q$, is kept above its natural rate, $Q N$ (correspondingly, if unemployment is kept below its natural rate), then accelerating inflation will eventually result. If $Q$ is kept below $Q N$ (correspondingly, if unemployment is kept above its natural rate) the inflation rate will eventually decline. When $Q$ is held equal to $Q N$, any inflation rate may persist indefinitely.

While conventional popularity functions assume that voters simply punish inflation and reward output or low unemployment, voters who understand the long- and short-run relationships noted above would evaluate policymakers differently. Inflation in a given period is largely determined by past expectations of inflation, which cannot easily be controlled by current policy choices. Expected inflation may be the result of mistakes made by past policymakers, and sophisticated voters will not punish the current administration for the mistakes of predecessors. Sophisticated voters might also refrain from rewarding higher values of $Q$, since values of $Q$ greater than $Q N$ eventually result in accelerating inflation. In short, sophisticated voters recognize that short-run policy choices are constrained to points on a short-run Phillips curve, and they will reward or punish according to whether the chosen point promotes movement toward desired long-run outcomes. ${ }^{6}$

\footnotetext{
${ }^{5}$ Recent estimates, including those of Gordon (1980) and MacRae (1981), suggest that the long-run Phillips curve is nearly vertical; however, our analysis does not crucially depend on this assumption.

${ }^{6}$ Because equation (1) is stochastic, we should also consider whether or not rational voters would reward favorable error terms. If error terms primarily represent exogenous shocks which are outside the policymaker's control, then there is no reason to reward or punish an incumbent politician for them. On the other hand, a president might be able to use policies besides aggregate demand management to improve the unemployment-inflation tradeoff, so voters might rationally attribute favorable error terms to the president's actions. We have decided not to include Phillips curve residuals as explanatory variables for popularity in the sophisticated voter model because: (1) it is likely that error terms resulted largely from exogenous shocks during the time period studied, and (2) since we wish to be conservative in accepting the hypothesis of sophisticated voters, it is preferable to estimate a strong version of the model. Including Phillips curve residuals as an additional explanatory variable would blur some of the distinction between the sophisticated voter model and the conventional naive voter model.
}

Faced with severe current inflation, sophisticated voters would prefer to see the government pursue contractionary policies (i.e., make $Z_{t}$ less than 1) in order to gradually move down the long-run Phillips curve. In general, the higher the current rate of inflation, the more severe the contractionary policy should be. Similarly, deflation should be countered with stimulative policies. As an approximation, we assume that the optimal value of the control variable $Z_{t}$, denoted $Z_{t}^{*}$, is determined according to the following linear feedback rule:

$$
Z_{t}^{*}=d_{0}+d_{1} \dot{P}_{t-1}, \quad d_{0} \geq 0, d_{1} \leq 0
$$

where the slope parameter $d_{1}$ will be larger in absolute value the greater the aversion of voters to inflation relative to recession. The linear relationship specified in (3) should provide a reasonable approximation for the optimal $Z_{t}^{*}$ which could be computed as the solution to a control problem like those proposed by Fair (1978b) and MacRae (1977). ${ }^{7}$ In fact, for the particular model and objective function employed by MacRae (1977), the optimal level of excess supply is simply a linear function of the inflation rate in the preceding period (equation (15), p. 247).

An interesting special case arises when the intercept, $d_{0}$, is equal to zero. In this case, starting from zero inflation, voters find that the benefits of temporarily increasing output above its natural rate are exceeded by the welfare costs of the resulting permanent inflation. Voters would therefore desire an inflation rate of zero and growth of $Q$ to match $Q N$ in the long run. The arguments of Feldstein (1979) suggest that for a growing economy this case is especially compelling, ${ }^{8}$ and it will receive special attention in the following empirical analysis. In the case where $d_{0}$ exceeds zero, voters are willing to accept some permanent inflation in return for a temporary excess of $Q$ over $Q N$, and therefore would not wish to move to the horizontal

\footnotetext{
${ }^{7}$ Gramlich (1979), in a study of optimal responses to price shocks, also chose to examine linear feedback rules as approximate solutions to optimal control problems.

${ }^{8}$ Feldstein assumes that the welfare cost induced by permanent inflation will grow in proportion to the economy. If the growth rate of the economy exceeds the real social discount rate, which Feldstein argues is likely, then the present value of the welfare cost of an increase in permanent inflation above its target level (which we assume is zero) is infinite, and must exceed the benefits of the corresponding temporary increase in output.
} 
intercept of the long-run Phillips curve. The case where $d_{0}$ is less than zero is implausible, since it implies that, starting from a zero inflation position, voters would opt for recession and deflation.

To measure economic performance, it is appropriate to judge policymakers on the basis of how far they deviate from the optimal policy $Z_{t}^{*}$. In our empirical work, a performance measure appropriate for sophisticated voters is provided by

$$
S_{t}=\left(Z_{t}-Z_{t}^{*}\right)^{2}=\left(Z_{t}-d_{0}-d_{1} \dot{P}_{t-1}\right)^{2} \text {. }
$$

Higher values of $S_{t}$ denote poorer performance. Clearly voters will not always reward increases in output; if inflation is a serious problem they reward contractionary policies, because they understand its beneficial long-run consequences.

\section{Specification of the Popularity Model}

We make use of a popularity function which is similar to that developed by Hibbs (1982a, 1982b). The general formulation of the popularity function is provided by (5):

$$
\begin{aligned}
\text { POP }_{t}= & \sum_{k=0}^{31}\left(a_{0}+A X_{t-k}\right) D_{t, t-k-1} g^{k} \\
& +b_{0}+B V_{t}+u_{t}
\end{aligned}
$$

where

$$
\begin{aligned}
& X_{t}= \text { a vector of variables indicative of } \\
& \text { economic performance } \\
& V_{t}= \text { a vector of noneconomic variables } \\
& \text { affecting popularity } \\
& D_{t, t-k-1}= \text { a dummy variable equal to } 1 \text { if the } \\
& \text { administration in office in period } t \\
& \text { was also in office in period } t-k-1, \\
& \text { and equal to }-1 \text { otherwise } \\
& A, B \quad \text { are vectors of parameters } \\
& a_{0}, b_{0}, g \quad \text { are scalar parameters. }
\end{aligned}
$$

Equation (5) says that popularity at time $t$ is a function of economic performance in the 32 quarters extending from the current quarter backwards in time. Presumably the weighting parameter $g$ is between 0 and 1 , so that voters weight recent periods more heavily. Our estimates of $g$ usually imply that the weight attached to a period 32 quarters back in time is small, so the assump-

\footnotetext{
${ }^{9}$ Kennedy-Johnson are considered a single administration, as are Nixon-Ford. This is appropriate since neither succeeding president drastically altered the economic policies of his predecessor.
}

tion of a finite 32 period "memory" is not very restrictive. The inclusion of the dummy variable implies that the current administration will be less popular if its performance is judged to be poor, but it will be more popular if the performance of previous administrations was poor. ${ }^{10}$ "Honeymoon" effects for an incoming administration may therefore be either positive or negative, depending on how the preceding administration fared.

Our estimated popularity functions will make use of the general formulation of (3) in all cases; differences in the models involve the selection of variables to be included in $X_{t}$. In the naive voter model the inflation rate $\dot{P}$ and the output ratio $Q / Q N$ are included as performance measures, so the equation to be estimated is

$$
\begin{aligned}
\text { POP }_{t}= & \sum_{k=0}^{31}\left(a_{0}+a_{1} \dot{P}_{t-k}+a_{2} Q_{t-k} / Q N_{t-k}\right) \\
& \times D_{t, t-k-1} g^{k}+b_{0}+B V_{t}+u_{t} .
\end{aligned}
$$

The conventional hypotheses predict that higher output will be rewarded and higher inflation punished."

In the sophisticated voter model $X_{t}$ includes only the performance measure $S_{t}$ defined in (4). Substituting (4) into (5), the sophisticated voter model can be written as

$$
\begin{aligned}
\text { POP }_{t}= & \sum_{k=0}^{31}\left[a_{0}+c_{0}\left(Z_{t-k}-d_{0}-d_{1} \dot{P}_{t-k-1}\right)^{2}\right] \\
& \times D_{t, t-k-1} g^{k}+b_{0}+B V_{t}+u_{t} .
\end{aligned}
$$

The parameters $d_{0}$ and $d_{1}$, which appear in the optimal feedback rule, can be estimated along with the other parameters appearing in the popularity function.

\section{Empirical Results}

In all equations, the dependent variable, $P O P_{t}$, is defined as the fraction of the Gallup Poll respondents who answered "yes" when asked if they

\footnotetext{
${ }^{10}$ The specification implies that responsibility for the first quarter of an incoming administration's tenure is assigned to the preceding administration. Given the existence of lags in implementing policies and the fact that the outgoing president is in office for the first three weeks of the quarter, this is a reasonable assumption.

${ }^{11}$ We have also estimated equations in which $Q / Q N$ was replaced by (1) the ratio of unemployment to the natural rate of unemployment, (2) the percentage rate of growth of $Q$, and (3) the unemployment rate. Results from all of these equations are very similar, and would not alter any of our conclusions.
} 
approved of the way the incumbent was handling his job as president. ${ }^{12} \mathrm{We}$ assume that poll respondents are representative of the voter population and that their responses are based upon the same criteria as voting decisions. The economic variables consist of the quarterly inflation rate $(\dot{P})$ computed from the GNP deflator, real GNP $(Q)$, and estimates of the natural rate of output $(Q N)$ obtained from a mimeographed supplement to Gordon (1981). Non-economic variables in the vector $V_{t}$ include dummy variables for each president, to reflect personal attributes which affect popularity. In addition, $1 /$ TOF (where TOF is the number of periods the president has been in office) is included to account for honeymoon effects which are not interactive with performance. We have already noted that our specification permits honeymoon effects related to the performance of the previous administration, but it is possible that independent honeymoon effects occur. We also include variables to account for the effects of important political events. To proxy dissatisfaction with involvement in the Viet Nam War, we include $K I L L E D$, the number of servicemen killed in action during the quarter. ${ }^{13} \mathrm{We}$ also include a dummy variable for the Watergate period, $W G$, which equals one for 1973IV through 1974II (i.e., from the firing of Archibald Cox until Nixon's resignation) and is otherwise equal to zero.

Table 1 reports estimates of the popularity functions. We have estimated models corresponding to the "naive" voter hypothesis and to our "sophisticated" voter hypothesis, and for each model we report estimates which respectively assume no serial correlation and first order serial correlation of the error terms. All equations are estimated for the 1957 I to 1980 IV period. ${ }^{14}$ The same variables

12 Hibbs has noted that $P O P_{t}$ is always between 0 and $100 \%$, and he constrains predicted values of $P O P_{t}$ to be in those bounds by using $\log \left(P O P_{t} /\left(1-P O P_{t}\right)\right)$ as the dependent variable in his model. Since $P O P_{t}$ is always less than $80 \%$ and greater than $20 \%$ in our sample, imposing this constraint turns out to be of little importance. We have also estimated a number of equations using Hibbs' dependent variable and making corrections for heteroscedasticity, and all results were quite similar to those reported here. In the interest of simplicity, we report only those equations using $P O P_{t}$ as the dependent variable.

${ }^{13}$ Sources: Milstein (1974), U.S. Department of Commerce, Bureau of the Census (1980).

${ }^{14}$ Popularity data are unavailable for three observations. Because of these missing values, the procedure to correct for serial correlation is not strictly appropriate, and estimates should be regarded as suggestive. appear in the two models; only the form of the equation differs.

Columns (1) and (4) report nonlinear least squares estimates of the naive voter model. Under the assumption of no serial correlation, the estimates indicate that inflation has a significant effect in lowering popularity; however, the coefficient of the output variable has a surprising negative sign. When corrections are made for serial correlation, the signs remain the same for these two coefficients, but neither is significant.

Columns (2) and (5) report estimates of the general version of the sophisticated voter model. ${ }^{15}$ These estimates provide little apparent support for our hypotheses, since both $d_{0}$ and $d_{1}$ are incorrectly signed. Collinearity problems provide a possible explanation for the perverse results, however. In the sample period analyzed, deflation was a rarity. From the data alone, it may therefore be difficult to determine whether a preference for contractionary policies was motivated by a desire to fight inflation (indicated by a negative $d_{1}$ ) or simply a desire for recession regardless of the inflation rate (indicated by a negative $d_{0}$ ). The estimates suggest the latter.

We have previously noted, however, that a desire for recession when prices are stable is not sensible, so imposition of the constraint $d_{0}=0$ is theoretically justified. Columns (3) and (6) report estimates of the restricted model, which provide much stronger support for the sophisticated voter hypothesis. Estimates of $c_{0}$ (indicating how voters respond to suboptimal performance) and $d_{1}$ (the inflation aversion parameter) are negative, as hypothesized. Estimates of $d_{1}$ are significant at the 0.05 level in both columns (3) and (6), while the estimate of $c_{0}$ is significant at the 0.05 level in column (3) and falls just short of significance at the 0.10 level in column (6). $R^{2} s$ for the restricted equations differ little from those of their unrestricted counterparts, and are higher than those obtained for the corresponding naive voter equations, which have an equal number of parameters.

\footnotetext{
${ }^{15}$ To obtain starting values for the nonlinear least squares algorithm, a grid of possible values for $d_{0}, d_{1}$, and $g$ was searched. The grid revealed the presence of local, as well as global, minima for the sum of squared residuals. Interestingly, for the case where $d_{0}$ is constrained to equal zero, parameter values at a local minimum provided almost as good a fit as the global minimum reported in the table, but indicated much milder inflation aversion.
} 
Table 1. - Estimated Presidential Popularity Functions

(asymptotic $t$-statistics in parentheses)

\begin{tabular}{|c|c|c|c|c|c|c|}
\hline \multirow[b]{2}{*}{$\begin{array}{c}\text { Parameter/ } \\
\text { Independent Variable }\end{array}$} & \multicolumn{3}{|c|}{ Not Corrected for Serial Correlation } & \multicolumn{3}{|c|}{ Corrected for Serial Correlation } \\
\hline & $\begin{array}{l}\text { Naive } \\
\text { (1) }\end{array}$ & $\begin{array}{l}\text { Sophisticated } \\
\text { (2) }\end{array}$ & $\begin{array}{c}\text { Sophisticated } \\
\text { (3) }\end{array}$ & $\begin{array}{l}\text { Naive } \\
(4)\end{array}$ & $\begin{array}{c}\text { Sophisticated } \\
\text { (5) }\end{array}$ & $\begin{array}{c}\text { Sophisticated } \\
\text { (6) }\end{array}$ \\
\hline \multirow[t]{2}{*}{$b_{0}$} & 0.6820 & 0.7366 & 0.6549 & 0.6999 & 0.7136 & 0.6279 \\
\hline & $(19.4040)^{\mathrm{a}}$ & $(25.0275)^{\mathrm{a}}$ & $(16.7755)^{\mathrm{a}}$ & $(13.6420)^{\mathrm{a}}$ & $(16.6798)^{\mathrm{a}}$ & $(9.6362)^{\mathrm{a}}$ \\
\hline \multirow[t]{2}{*}{$a_{0}$} & 0.1020 & -0.0127 & -0.0025 & 0.1082 & -0.0052 & -0.0002 \\
\hline & $(1.5670)$ & $(-2.2912)^{\mathrm{a}}$ & $(-0.6139)$ & $(1.0582)$ & $(1.6314)$ & $(-0.0606)$ \\
\hline \multirow[t]{2}{*}{$c_{0}$} & - & -18.2171 & -2.4352 & - & -10.2100 & -2.8662 \\
\hline & - & $(-3.5425)^{\mathrm{a}}$ & $(-1.9857)^{\mathrm{a}}$ & - & $(-1.6314)$ & $(-1.5922)$ \\
\hline \multirow[t]{2}{*}{$d_{0}$} & - & -0.0140 & - & - & -0.0201 & - \\
\hline & - & $(-2.2516)^{\mathrm{a}}$ & - & - & $(-1.1789)$ & - \\
\hline \multirow[t]{2}{*}{$d_{1}$} & - & 0.0024 & -0.0106 & - & 0.0036 & -0.0095 \\
\hline & - & $(2.1345)^{\mathrm{a}}$ & $(-3.8972)^{\mathrm{a}}$ & - & $(1.1763)$ & $(-3.3196)^{\mathrm{a}}$ \\
\hline \multirow[t]{2}{*}{$g^{\mathrm{b}}$} & 0.9268 & 0.8323 & 0.9255 & 0.9770 & 0.9207 & 0.9709 \\
\hline & $(2.2210)^{\mathrm{a}}$ & $(5.0030)^{\mathrm{a}}$ & $(2.7886)^{a}$ & $(0.9006)$ & $(1.9575)^{\mathrm{a}}$ & $(1.7037)^{\mathrm{a}}$ \\
\hline \multirow[t]{2}{*}{$P$} & -0.0017 & - & - & -0.0012 & - & - \\
\hline & $(-2.4408)^{\mathrm{a}}$ & - & - & $(-1.1595)$ & - & - \\
\hline \multirow[t]{2}{*}{$Q / Q N$} & -0.1063 & - & - & -0.1121 & - & - \\
\hline & $(-1.6532)^{\mathrm{a}}$ & - & - & $(-1.1055)$ & - & - \\
\hline \multirow[t]{2}{*}{$1 / T O F$} & 0.0858 & -0.0590 & 0.0948 & 0.0472 & 0.0015 & 0.0643 \\
\hline & $(2.0645)^{\mathrm{a}}$ & $(-1.1313)$ & $(2.3213)^{\mathrm{a}}$ & $(1.0517)$ & $(0.0301)$ & $(1.4537)$ \\
\hline \multirow[t]{2}{*}{ KILLED } & -0.0409 & -0.0383 & -0.0360 & -0.0172 & -0.0192 & -0.0190 \\
\hline & $(-4.3435)^{\mathrm{a}}$ & $(-4.3699)^{\mathrm{a}}$ & $(-3.9215)^{\mathrm{a}}$ & $(1.4061)$ & $(-1.6762)^{\mathrm{a}}$ & $(-1.6979)^{\mathrm{a}}$ \\
\hline \multirow[t]{2}{*}{$W G$} & -0.1661 & -0.2088 & -0.1446 & -0.0964 & -0.1234 & -0.0928 \\
\hline & $(-3.6881)^{\mathrm{a}}$ & $(-5.3877)^{\mathrm{a}}$ & $(-3.3332)^{\mathrm{a}}$ & $(-1.8016)^{\mathrm{a}}$ & $(-2.5063)^{\mathrm{a}}$ & $(-1.8749)^{\mathrm{a}}$ \\
\hline \multirow[t]{2}{*}{$K E N N E D Y$} & -0.0289 & -0.0279 & -0.0045 & -0.1044 & -0.0743 & -0.0137 \\
\hline & $(-0.6987)$ & $(-1.0077)$ & $(-0.1037)$ & $(-1.3761)$ & $(-1.3237)$ & $(-0.1556)$ \\
\hline \multirow[t]{2}{*}{ JOHNSON } & 0.0125 & 0.0797 & 0.0186 & -0.0067 & 0.0368 & 0.0416 \\
\hline & $(0.4528)^{\mathrm{a}}$ & $(2.2933)^{\mathrm{a}}$ & $(0.7441)$ & $(-0.1160)$ & $(0.7557)$ & $(0.7061)$ \\
\hline \multirow[t]{2}{*}{$N I X O N$} & -0.1160 & -0.1429 & -0.1114 & -0.2216 & -0.2288 & -0.1637 \\
\hline & $(-2.8772)^{\mathrm{a}}$ & $(-4.7842)^{\mathrm{a}}$ & $(-3.1459)^{\mathrm{a}}$ & $(-3.0495)^{\mathrm{a}}$ & $(-3.7500)^{\mathrm{a}}$ & $(-2.5841)^{\mathrm{a}}$ \\
\hline \multirow[t]{2}{*}{ FORD } & -0.0663 & 0.0209 & -0.0516 & -0.0260 & -0.0016 & 0.0230 \\
\hline & $(-1.5098)$ & $(0.4536)$ & $(-1.1539)$ & $(-0.3348)$ & $(-0.0266)$ & $(0.2860)$ \\
\hline$C A R T E R$ & -0.2353 & -0.2723 & -0.1994 & -0.3226 & -0.3419 & -0.2298 \\
\hline & $(-5.5936)^{\mathrm{a}}$ & $(-8.4383)^{\mathrm{a}}$ & $(-4.8132)^{\mathrm{a}}$ & $(-4.7140)^{\mathrm{a}}$ & $(-5.5490)^{\mathrm{a}}$ & $(-3.0505)^{\mathrm{a}}$ \\
\hline$R^{2}$ & 0.821 & 0.845 & 0.829 & 0.628 & 0.679 & 0.653 \\
\hline D.W. & 1.18 & 1.36 & 1.21 & - & - & - \\
\hline
\end{tabular}

${ }^{\text {a }}$ Significant at the 0.10 level.

$\mathrm{b}$ Reported $t$-statistic is for the test of $\mathrm{H}_{0}: g=1$

Clearly these results show that the sophisticated voter hypothesis is consistent with the data, and performs as well or better than the naive voter hypothesis.

With $d_{1}=-0.0106$, the estimate obtained from column (3), the model implies that voters would like to see actual output be $10.6 \%$ below the natural rate of output when the inflation rate is $10 \%$. Translating via Okun's Law, this would imply that voters desire an unemployment rate about 3.5\% above its natural rate. Although this implies that voters desire a severe recession when inflation is high, it cannot be considered a completely unrea- sonable estimate. ${ }^{16}$ The estimate of $d_{1}$ from column (6) implies slightly weaker aversion to inflation.

The estimate of $c_{0}$ from column (3) indicates that if the actual current $Q / Q N$ were to deviate from the voters' perceived optimal $Q / Q N$ by 0.05 , then the resulting popularity rating would be 0.61 percentage points lower than that which would

\footnotetext{
${ }^{16}$ Some officials in the Reagan administration seemed willing to tolerate unemployment of more than $10 \%$ (probably $3 \%$ to $4 \%$ above the natural rate) to fight inflation in 1982. If administration economic experts are willing to accept such a tradeoff, rational voters might very well do so also.
} 
have resulted had optimal policies been chosen. Of course if the administration consistently deviates from the optimum by that amount, the cumulative popularity consequences are much more severe. After 8 years, the cumulative effect is a popularity loss of about 7.3 percentage points. Somewhat larger effects are implied by estimates in column (6).

Conclusions regarding the noneconomic variables are similar for all six equations. The coefficients of the Watergate and Viet Nam War variables are negative, as anticipated, and generally significant. The presidential dummies are also often significant. There is some evidence of honeymoon effects unrelated to past economic performance, since the coefficient of $1 / T O F$ is sometimes significantly positive. Estimates of the weighting parameter $g$ range from 0.83 to 0.98 , generally a bit higher than the estimates provided by Hibbs (1982a).

\section{Evaluating the Performance of Different Administrations}

Using estimates of $d_{0}$ and $d_{1}$ and historical data for $Q$ and $Q N$, we can construct predicted values of $S_{t}$, denoted $\hat{S}_{t}$, by using the definition provided by equation (4). By comparing mean values of $\hat{S}_{t}$ over different administrations, we can compare the economic performance of those administrations as judged by sophisticated voters. Our performance measure is similar to that proposed by Fair (1978b). Like that measure, ous s does not punish an administration for inflation caused by predecessors, and it incorporates a concern for future outcomes. Unlike Fair's measure, preferences regarding inflation and output are based on empirical evidence (i.e., the estimate of $d_{1}$ ) in our measure. Fair's performance measures were constructed for two alternative but arbitrary parameter choices which indicated relative preferences for output and inflation, and he made use of a large and realistic model of the economy to provide the constraints on feasible outcomes.

Table 2 provides mean values of $\hat{S}_{t}$ calculated using the estimate of $d_{1}$ obtained from column (3) of table 1 and setting $d_{0}$ equal to zero. ${ }^{17}$ The table

\footnotetext{
${ }^{17}$ The results were similar when we used estimates obtained from equation (6).
}

Table 2. - Economic Performance of Presidential ADMINISTRATIONS

\begin{tabular}{lrcc}
\hline \hline Administration & Mean $\hat{S}_{t}$ & $\begin{array}{c}\text { Rank based } \\
\text { on Mean } \hat{S}_{t}\end{array}$ & $\begin{array}{c}\text { Rank by } \\
\text { Fair (1978b) }\end{array}$ \\
\hline Eisenhower I & $17.18 \times 10^{-4}$ & 3 & 2 \\
Eisenhower II & $7.38 \times 10^{-4}$ & 2 & 5 \\
Kennedy-Johnson & $4.31 \times 10^{-4}$ & 1 & 4 \\
Johnson & $59.39 \times 10^{-4}$ & 7 & 3 \\
Nixon & $38.79 \times 10^{-4}$ & 4 & 1 \\
Nixon-Ford & $43.49 \times 10^{-4}$ & 5 & Not ranked \\
Carter & $52.47 \times 10^{-4}$ & 6 & Not ranked \\
\hline
\end{tabular}

also provides rankings of the administrations, and compares these rankings with those provided by Fair (1978b, p. 306). Since our estimates indicate a rather strong aversion to inflation, we provide Fair's rankings based on a stronger aversion to inflation.

The results show that Kennedy-Johnson and Eisenhower II rank highest in economic performance. In these administrations, mild inflation was countered with mild slackness in the economy. The worst performance was provided by the Johnson administration. The macroeconomic stimulus resulting from Viet Nam War spending is often pointed to as a source of subsequent inflation, and this is reflected in our rankings. Carter also gets a low rating, primarily for failing to impose a sufficiently contractionary stance in the face of rapid inflation. Fair's rankings differ substantially from ours. This may result from a stronger aversion to inflation implicit in our measure, or relatively small long- and short-run inflationary costs associated with high levels of output in Fair's model of the economy.

\section{Conclusions}

Our results show that data on Presidential popularity are consistent with the hypothesis that voters are concerned with the future consequences of current economic policy choices and are aware of the nature of constraints imposed by economic reality. Our sophisticated voter model performs as well or better than a conventional popularity model which assumes that voters are myopic or have limited knowledge of the workings of the economy. Our conclusions are therefore similar to those of MacRae (1977, 1981), who found a limited potential for politically motivated business cycles. 
Of course, the results do not prove that the electorate is "sophisticated." We have not examined all possible specifications for popularity functions, and we have examined just one set of data. We have not attempted to account for changing voter preferences over time, for changes in the structure of the economy, or for differing preferences for various subgroups in the population. In future work we plan to address some of these problems and investigate other sources of data which researchers have employed in studying the response of the populace to macroeconomic performance. In the meantime, however, we should be wary of accepting the naive voter hypothesis which much previous research professes to support.

\section{REFERENCES}

Arcelus, Francisco, and Allan H. Meltzer, "The Effect of Aggregate Economic Variables on Congressional Elections," The American Political Science Review 69 (Dec. 1975), 1232-1239.

Bloom, Howard S., and H. Douglas Price, "Voter Response to Short-run Economic Conditions: The Asymmetric Effect of Prosperity and Recession," The American Political Science Review 69 (Dec. 1975), 1240-1254.

Fair, Ray C., "The Effect of Economic Events on Votes for President," this Review 60 (May 1978a), 159-173.

, "The Use of Optimal Control Techniques to Measure Economic Performance," International Economic Review 19 (June 1978b), 289-309.

Feldstein, Martin, "The Welfare Cost of Permanent Inflation and Optimal Short-run Economic Policy," Journal of Political Economy 87 (Aug. 1979), 749-768.

Fischer, Stanley, "Long-term contracts, Rational Expectations, and the Optimal Money Supply Rule," Journal of Political Economy 85 (Feb. 1977), 191-205.

Frey, Bruno S., and Friedrich Schneider, “An Empirical Study of Politico-Economic Interaction in the U.S.," this REVIEW 60 (May 1978), 174-183.

Gordon, Robert J., "A Consistent Characterization of a Near Century of Price Behavior," American Economic Review 70 (May 1980), 243-249.

, Macroeconomics (Boston: Little, Brown and Company, 1981).

Gramlich, Edward M., "Macro Policy Responses to Price Shocks," Brookings Papers on Economic Activity (1, 1979), $125-166$.

Hibbs, Douglas A., "The Dynamics of Political Support for American Presidents among Occupational and Partisan Groups," American Journal of Political Science 26 (May 1982a), 312-332.

, "On the Demand for Economic Outcomes: Macroeconomic Performance and Mass Political Support in the United States, Great Britain, and Germany," Journal of Politics 44 (May 1982b), 426-462.

Kramer, Gerald H., "Short-term Fluctuations in U.S. Voting Behavior, 1896-1964," American Political Science Review 65 (Mar. 1971), 131-143.

MacRae, C. Duncan, "A Political Model of the Business Cycle," Journal of Political Economy 85 (Apr. 1977), 239-263. , "On the Political Business Cycle," in Douglas A. Hibbs and Heino Fassbender (eds.), Contemporary Political Economy (Amsterdam: North-Holland Publishing Company, 1981).

Maloney, Kevin, and Michael L. Smirlock, "Business Cycles and the Political Process," Southern Economic Journal 48 (Oct. 1981), 377-392.

Milstein, Jeffrey, Dynamics of the Vietnam War (Columbus: Ohio State University Press, 1974).

Nordhaus, William H., "The Political Business Cycle," Review of Economic Studies 42 (Apr. 1975), 169-189.

Pollard, Walker A., "Effects of Economic Conditions on Elections: A Study Controlling for Political Variables: An Update Through 1976," mimeographed, Washington University, 1981a. , "Macroeconomic Effects on U.S. Presidential Elections: A Study of Pooled State-Level and Time-Series Data, 1932-1976," mimeographed, Washington University, $1981 \mathrm{lb}$.

Tufte, Edward R., Political Control of the Economy (Princeton: Princeton University Press, 1978).

U.S. Department of Commerce, Bureau of the Census, Statistical Abstract of the U.S., 1980. 